\title{
Vascular Protection Following Cerebral Ischemia and Reperfusion
}

\section{Sara Morales Palomares and Marilyn J. Cipolla*}

Departments of Neurology, Obstetrics, Gynecology \& Reproductive Sciences and Pharmacology, University of Vermont, Burlington, Vermont

\begin{abstract}
Despite considerable research that has contributed to a better understanding of the pathophysiology of stroke, translation of this knowledge into effective therapies has largely failed. The only effective treatment for ischemic stroke is rapid recanalization of an occluded vessel by dissolving the clot with tissue plasminogen activator (tPA). However, stroke adversely affects vascular function as well that can cause secondary brain injury and limit treatment that depends on a patent vasculature. In middle cerebral arteries (MCA), ischemia/reperfusion (I/R) causes loss of myogenic tone, vascular paralysis, and endothelial dysfunction that can lead to loss of autoregulation. In contrast, brain parenchymal arterioles retain considerable tone during $\mathrm{I} / \mathrm{R}$ that likely contributes to expansion of the infarct into the penumbra. Microvascular dysregulation also occurs during ischemic stroke that causes edema and hemorrhage, exacerbating the primary insult. Ischemic injury of vasculature is progressive with longer duration of I/R. Early postischemic reperfusion has beneficial effects on stroke outcome but can impair vascular function and exacerbate ischemic injury after longer durations of I/R. This review focuses on current knowledge on the effects of I/R on the structure and function of different vascular segments in the brain and highlight some of the more promising targets for vascular protection.
\end{abstract}

\section{Introduction}

Stroke is a vascular disorder that adversely affects neurons to cause ischemic brain injury. Both macro- and micro-vascular dysregulation occurs during $\mathrm{I} / \mathrm{R}$ that can exacerbate the primary insult as well as cause secondary brain injury such as edema and hemorrhage. The cerebral vasculature has a central role in stroke injury since the core infarction is dependent on the depth and duration of ischemia. In addition, the only effective treatment for ischemic stroke is a vascular one-dissolving the clot with tPA and rapid restoration of blood flow. In addition, any neuroprotective therapy depends on a patent and functional vasculature, highlighting the importance of vascular protection as a therapeutic approach to limiting stroke damage.

Similar to neurons, the brain vasculature is a major target of I/R injury. Cerebrovascular damage occurs early during focal ischemia and is progressive with longer durations of I/R. Reperfusion after short durations of ischemia can salvage damaged brain tissue; however, reperfusion after longer periods of ischemia is not entirely beneficial. Postischemic reperfusion can impair autoregulatory mechanisms and promote loss of control of cerebral blood flow (CBF) that exacerbates ischemic injury [1-7]. Thus, $\mathrm{I} / \mathrm{R}$ affect the cerebral arteries and arterioles that control both the extent of ischemia and the degree of reperfusion $[2,8]$. In this review, we focus on current knowledge on the effects of $\mathrm{I} / \mathrm{R}$ on the structure and function of the cerebral vasculature and highlight some of the more promising targets for vascular protection.

\section{Hemodynamics during $I / R$}

In normotensive adults, CBF is maintained at $\sim 50 \mathrm{ml} / 100 \mathrm{~g}$ of brain tissue per minute, provided cerebral perfusion pressure is in the range of $\sim 60$ to $160 \mathrm{mmHg}$ [9]. Above and below this limit, autoregulation is lost and CBF becomes dependent on mean arterial pressure linearly [10]. Blood-brain barrier (BBB) disruption and edema formation can occur when autoregulatory mechanisms are not effective at maintaining appropriate cerebrovascular resistance (CVR) [11-14]. Cerebral ischemia causes autoregulatory failure due to several vasodilatory mechanisms that are invoked in order to increase flow to the ischemic region. For example, occlusion of an artery decreases perfusion pressure downstream that causes myogenic vasodilation of arteries and arterioles. Lactic acidosis and carbon dioxide also build due to decreased clearance, further promoting vasodilation and loss of autoregulation. Reperfusion of an ischemic region can result in hyperemia due to vascular paralysis associated with hypoxia/ischemiainduced vasodilation [15-18]. Hyperemia is a common in the acute phase of stroke, occurring in $\sim 40-50 \%$ of patients within 3 days after stroke $[11,18]$. Cerebral hyperemia can exacerbate neuronal injury during reperfusion and promote $\mathrm{BBB}$ disruption and brain edema due to diminished CVR that exposes the microcirculation to excessive perfusion pressure $[11,19]$.

\section{Pathophysiological effects of $I / R$ on cerebral arteries}

The cerebral circulation is unique in that the large vessels (extracranial and intracranial pial vessels including carotids and arteries of the circle of Willis) contribute $~ 50 \%$ of total CVR [20,21]. The unusually prominent role of large arteries in vascular resistance helps to maintain CBF under conditions that change blood flow locally, but also protects downstream vessels during changes in arterial pressure [22-24]. Cerebral hyperemia during reperfusion is due to vasodilatation of cerebral arteries and arterioles in response to ischemia and/or reperfusion. For example, the caliber of the MCA increases $172 \%$ and $\mathrm{CBF}$ by $588 \%$ of baseline after 30 minutes of reperfusion [7]

*Corresponding author: Marilyn J. Cipolla, Department of Neurology, University of Vermont, Burlington, Tel: 802-656-9714; E-mail: Marilyn.Cipolla@ uvm.edu

Received June 30, 2011; Accepted July 21, 2011; Published September 20, 2011 Citation: Palomares SM, Cipolla MJ (2011) Vascular Protection Following Cerebra Ischemia and Reperfusion. J Neurol Neurophysiol S1. doi:10.4172/2155-9562.S1. 004

Copyright: (C) 2011 Palomares SM, et al. This is an open-access article distributed under the terms of the Creative Commons Attribution License, which permits unrestricted use, distribution, and reproduction in any medium, provided the original author and source are credited. 
Citation: Palomares SM, Cipolla MJ (2011) Vascular Protection Following Cerebral Ischemia and Reperfusion. J Neurol Neurophysiol S1. doi:10.4172/2155-9562.S1-004

Thus, studies have focused on the underlying mechanisms by which I/R affect MCA diameter regulation and loss of myogenic tone. The significant contribution of large cerebral arteries to CVR, including MCA, makes understanding structural and functional changes in these vessels in response to $\mathrm{I} / \mathrm{R}$ relevant.

Myogenic responses during I/R: The myogenic response is a critical component of resistance artery function and involves two events: the change in diameter in response to a change in pressure (myogenic reactivity) and the state of partial constriction at a constant pressure (myogenic tone) [25]. Both myogenic tone and reactivity of cerebral arteries contribute to CVR and autoregulation of CBF that is facilitated by vascular smooth muscle that contracts to increased pressure and relaxes in response to decreased pressure $[20,23,24,26]$. The cerebral arteries have considerable myogenic tone, thus contributing to CVR. Postischemic reperfusion impairs myogenic responses in MCA that is dependent on the duration of I/R. Experimental models of transient focal ischemia have showed that after 2 hours of ischemia, myogenic tone in MCA was preserved after a brief reperfusion period of 1 minute, but was significantly lost after 24 hours [2]. The decrease in tone after 24 hours of reperfusion was associated with a significant loss of myogenic reactivity as well. This study demonstrated that there are threshold durations of ischemia and/or reperfusion for myogenic responses. For example, when the reperfusion duration was held constant at 24 hours and the ischemic duration increased, the threshold duration of

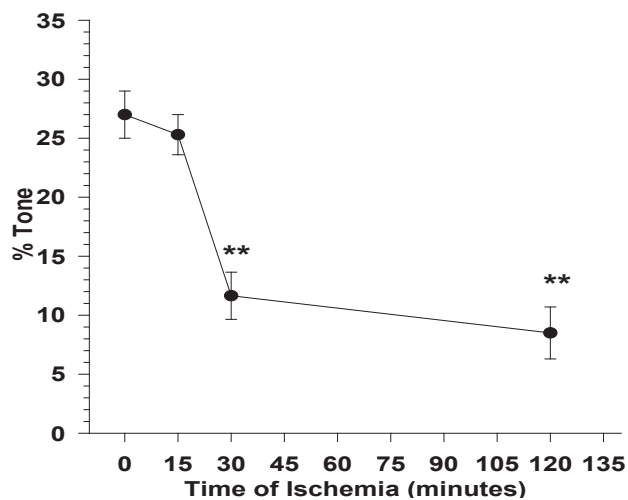

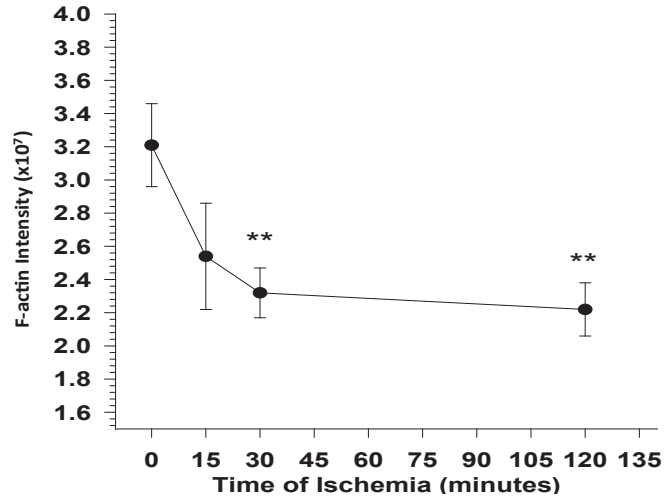

Figure 1: The effect of ischemic duration on myogenic responses and filamentous $\left(F_{-}\right)$actin content of middle cerebral arteries (MCA).

(A) Myogenic tone development in MCA exposed to different periods of ischemia, all with 24 hours of reperfusion: sham-operated control ( $\mathrm{n}=6$ ) and 15 ( $\mathrm{n}=6$ ), 30 $(n=7)$, and 120 minutes $(n=8)$ of ischemia. ${ }^{* *} P<0.01$ versus control.

(B) F-actin content in the same arteries shown in (A). Average F-actin content determined by fluorescence intensity of each group of ischemic arteries. ${ }^{\star *} \mathrm{P}<0.01$ versus control [27].

A

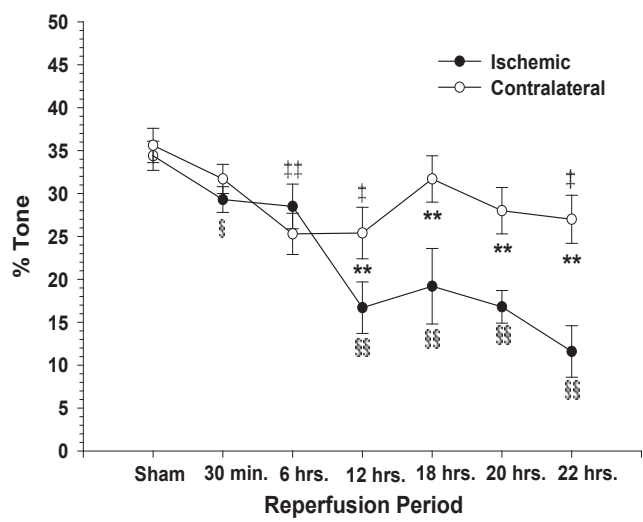

B

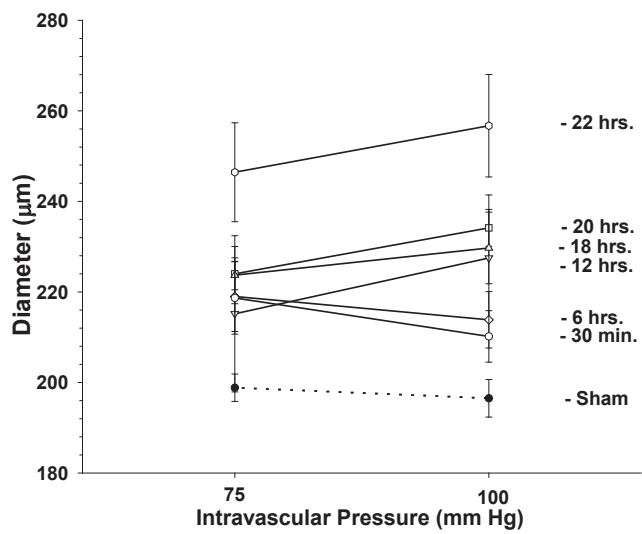

Figure 2: The effect of reperfusion duration on myogenic responses of MCA

(A) Graph showing percent tone of MCA exposed to different periods of reperfusion all with 30 minutes of ischemia compared with sham-operated control animals Shown are responses of MCA from both ipsilateral (closed circles) and contralateral (open circles) to occlusion. The amount of tone significantly diminished compared with sham-operated control in both contralateral and ischemic arteries as reperfusion duration increased. ${ }^{* *} \mathrm{P}<0.01$ contralateral versus ischemic; $+\mathrm{P}<0.05$ contralateral versus sham control; $\# \mathrm{P}<0.05$ contralateral versus sham control; $\$ \mathrm{P}<0.05$ ischemic versus sham control: $\$ \mathrm{P}<0.01$ ischemic versus sham control. (B) Graph showing diameter of MCA after step increases in transmural pressure from 75 to $125 \mathrm{~mm} \mathrm{Hg}$ after exposure to different periods of reperfusion all with 30 minutes of ischemia. Myogenic reactivity of MCA significantly diminished as reperfusion duration increased [28]. 
Citation: Palomares SM, Cipolla MJ (2011) Vascular Protection Following Cerebral Ischemia and Reperfusion. J Neurol Neurophysiol S1. doi:10.4172/2155-9562.S1-004

ischemia for myogenic tone was between 15 and 30 minutes (Figure 1A) [27]. This study also found that there was a significant positive correlation between diminished myogenic tone and filamentous (F-) actin in vascular smooth muscle (Figure 1B), suggesting that loss of F-actin is an underlying mechanism by which tone is diminished with ischemia.

The reperfusion threshold for myogenic responses in MCA was also determined when the ischemic duration was held constant at 30 minutes and reperfusion increased up to 22 hours. A significant loss in myogenic tone was noted between 6 and 12 hours of reperfusion (Figure 2A) [28]. Importantly, MCA on the contralateral side were also affected and had diminished tone as well, albeit to a lesser extent as the ipsilateral MCA. Similar to the effect on myogenic tone, myogenic reactivity was preserved at 6 hours of reperfusion, but diminished after 12 hours (Figure 2B). In addition, the slope of the pressure diameter curve became more positive as the reperfusion duration increased, demonstrating greater vascular damage with time that could impair autoregulation (Figure 3).

The pathophysiological mechanisms by which myogenic responses are lost after I/R are not completely clear and may be a combination of several processes. Vasoactive metabolites (eg. carbon dioxide, acidosis, etc.) produced during $\mathrm{I} / \mathrm{R}$ induce vasodilatation through relaxation of vascular smooth muscle, thus decreasing myogenic tone $[19,29]$. However, they cannot completely explain the prolonged vasodilatation that occurs, particularly since it persists in vitro when these metabolites are not present and in humans for 2 or 3 weeks after stroke [19,30]. Thus, more permanent damage likely occurs with prolonged I/R that causes vascular damage and decreased myogenic tone. For example, myogenic reactivity and tone have been shown to depend on an intact and dynamic actin cytoskeleton [31,32]. There is evidence that $\mathrm{I} / \mathrm{R}$-induced loss of F-actin content in vascular smooth muscle is an underlying mechanism by which tone is affected during stroke. In fact,

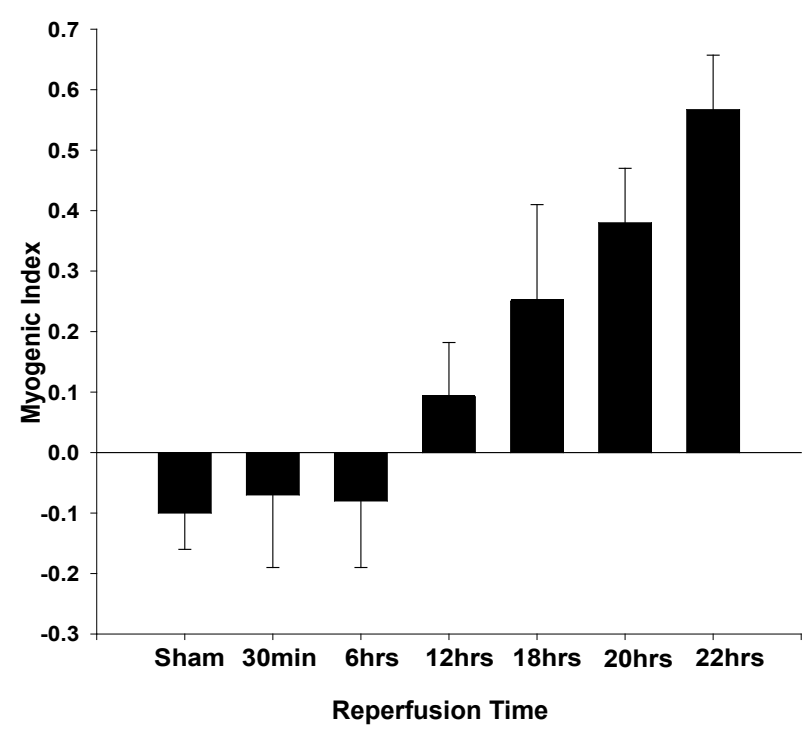

Figure 3: Graph showing slope of pressure-diameter curves for middle cerebral arteries (MCA) exposed to different periods of reperfusion.

Arteries that produced a negative slope are considered myogenic (shamoperated control, 30 minutes and 6 hours of reperfusion), whereas arteries that had a positive slope ( $\geq 12$ hours of reperfusion) had diminished myogenic behavior 28. ischemia disrupts actin filaments in several cell types and considered a major contributor to ischemic damage $[33,34]$. F-actin disruption during ischemia is likely due to decreased ATP levels that occurs within the first 15 minutes of cerebral ischemia [35]. During ischemia when ATP levels fall, ATP bound to actin is exchange for ADP, thereby releasing ATP for cellular use and causing actin polymers to dissociate [36]. This compensatory mechanism occurs in several cell types and may be a means by which cells preserve ATP, but sacrifice structure. In MCA, ischemia-induced loss of tone was related to a loss in vascular smooth muscle F-actin, suggesting this is a mechanism by which I/R causes loss of tone [27].

Oxidative stress is another important mechanism by which $I / R$ affect myogenic responses in MCA that also may be related to loss of F-actin. Production of reactive oxygen and nitrogen species (RONS) during $\mathrm{I} / \mathrm{R}$, including superoxide and nitric oxide that can react rapidly to produce peroxynitrite $\left(\mathrm{ONOO}^{-}\right)$, can affect tone [37]. Some studies have shown that high concentrations of $\mathrm{ONOO}^{-}$, similar to those produced during I/R [38], cause vasodilatation of cerebral arteries and loss of myogenic responses whereas, lower concentrations cause vasoconstriction [39]. The loss of myogenic tone in response to $\mathrm{ONOO}^{-}$exposure also positively correlates with a decrease in vascular smooth muscle F-actin and an increase in G-actin content, providing a mechanistic link between $\mathrm{ONOO}^{-}$and vascular dysfunction during I/R [39]. However, it is likely that the mechanism by which ischemia affects the cerebral circulation is different from that of reperfusion. For example, during ischemia there is upregulation of endothelial and neuronal nitric oxide synthase (eNOS and nNOS) activity that increases NO production within 10 minutes after focal ischemia that returns to normal at 60 minutes [40]. However, during reperfusion other mechanisms are prominent, including production of superoxide and hydrogen peroxide, that also dilate the cerebral vasculature by activating ATP-sensitive $\mathrm{K}^{+}\left(\mathrm{K}_{\text {ATP }}\right)$ and large-conductance $\mathrm{Ca}^{2+}$ activated $\mathrm{K}^{+}(\mathrm{BK})$ channels, respectively [41]. In addition, the hypoxic brain tissue synthesizes proinflammatory cytokines that can promote adhesion of circulating neutrophils to endothelial cells with subsequent release of additional pro-inflammatory mediators and generation of RONS by the infiltrated neutrophils, amplifying the inflammatory response [42-44]. Thus, RONS are an important therapeutic target for the vasculature as well as neuronal tissue during I/R.

The mechanism by which $\mathrm{ONOO}^{-}$causes vascular dysfunction has been studied extensively. ONOO- interacts with tissues, causing nitrosylation of tyrosine residues that can interfere with normal cellular function. Thus, ONOO causes nitrosylation of F-actin in vascular smooth muscle and loss of myogenic tone that was associated with depolymerization [45]. The loss vascular smooth muscle F-actin and myogenic tone evoked by $\mathrm{ONOO}^{-}$is similar to that seen after cerebral ischemia [27,39]. In addition, $\mathrm{ONOO}^{-}$can cause vasodilatation via other mechanisms that are not as paralyzing to the vasculature and may be more related to transient responses seen during shorter durations of I/R. ONOO- has been shown to activate BK channels in vascular smooth muscle and cause hyperpolarization, increase production of cyclic guanosyl-monophosphate (cGMP), decrease smooth muscle cell calcium through sarcoplasmic reticulum $\mathrm{Ca}^{2+}$-ATPase channel activity, and cause increased activation of myosin phosphatase activity $[46,47]$. Although $\mathrm{ONOO}^{-}$may be a therapeutic target to limit vascular paralysis during $I / R$, it is worth noting that other studies have shown that $\mathrm{ONOO}^{-}$is required for the ischemic tolerance and protection induced by lipopolysaccharide [48]. 
Effect of tPA on myogenic responses and vascular function during I/R: Currently, the only FDA approved treatment for ischemic stroke is to restore CBF using recombinant tPA (rtPA) to recanalize an occluded vessel. A major limitation of this pharmacologic treatment is that it is restricted to use within 4.5 hours of symptom onset because of the potential for adverse vascular effects (intracerebral hemorrhage) outside this treatment window $[49,50]$. Understanding how rtPA treatment affects MCA function during I/R may also be important for vascular protection. Treatment with rtPA alone significantly diminished myogenic reactivity in isolated MCA, a result that was additive if arteries were exposed to ischemia [51]. In addition, exposure to I/R or rtPA intraluminally caused endothelial dysfunction and significantly impaired vasodilation to acetylcholine that was also additive when ischemic arteries were perfused with rtPA [51]. These results suggest that rtPA administration adversely affects the cerebral vasculature, especially under ischemic conditions, and that treatment to protect the vasculature with rtPA use should be considered. Protecting the vasculature during tPA treatment may increase the time window for treatment and decrease its more deleterious effects that can counteract the beneficial effect of recanalization.

\section{The cerebral endothelium as a target for vascular protection during $\mathbf{I} / \mathbf{R}$}

The cerebral endothelium has a prominent role in numerous vascular functions including regulation of vascular tone [52,53]. In the brain, the endothelium has an unusually strong influence on resting vascular tone and $\mathrm{CBF}$ and is therefore of considerable interest as a therapeutic target during disease states [53]. The cerebral endothelium produces several vasoactive mediators, of which $\mathrm{NO}$ and endotheliumderived hyperpolarizing factor (EDHF) are some of the most important. Under resting conditions, basal NO production by the cerebral endothelium inhibits resting tone and thus affects CBF [54]. While the exact nature of EDHF is not clear, its hyperpolarizing influence appears to depend on the activity of calcium-activated small- and intermediateconductance potassium channels (SK and IK channels, also known as KCa2.3 and KCa3.1, respectively) due to the findings that specific blockade of these channels abrogates EDHF responses [55-59]. While EDHF does not appear to contribute to basal tone in cerebral arteries, inhibition of SK and IK channels causes constriction of penetrating arterioles under control conditions, suggesting that basal EDHF is present in these small vessels and inhibits basal tone [60,61]. Thus, both NO and EDHF should be considered during I/R because of their vasodilator influence.

Effect of I/R on eNOS: It is well-established that NO has an important role in the pathogenesis of brain injury during cerebral ischemia. Both nNOS and eNOS are activated during ischemia; however, they appear to have opposing effects [62-66]. For example, increased nNOS activity can cause neuronal injury, whereas eNOS activation has been shown to be protective during stroke [63-65]. Mice lacking eNOS expression showed a greater degree of hemodynamic compromise with smaller penumbra areas compared to wildtype, suggesting that eNOS activity is protective of the brain during focal ischemia by improving blood flow in the penumbra [63].

NO is an important target for stroke therapy because it has several beneficial effects on the vasculature, but can also cause damage. NO mediates vascular responses by causing vasodilatation, and inhibiting platelet aggregation and leukocyte adhesion. Thus, it can improve reperfusion blood flow through vasodilation and increasing collateral flow to the ischemic area but it also importantly prevents microvascular plugging by platelets and leukocytes $[67,68]$. However, as described above, NO can also react with superoxide to produce $\mathrm{ONOO}^{-}$which interacts with proteins, lipids, and DNA, and promotes cytotoxic and proinflammatory responses [69]. In addition, during cerebral ischemia the NOS substrate L-arginine and co-factors such as tetrahydrobiopterin $\left(\mathrm{BH}_{4}\right)$ are likely to be rate-limiting causing eNOS to generate superoxide (and hydrogen peroxide) instead of NO, thus promoting oxidative damage $[70,71]$.

Upregulation of eNOS occurs rapidly in the brain during focal ischemia and remains upregulated on the ischemic side of the brain as long as 7 days of reperfusion $[63,66,72]$. Despite the increase in eNOS expression, our own studies $[2,8,51]$ and numerous others [7376], have consistently found that postischemic reperfusion diminishes the influence of basal NO on tone and responsiveness of cerebral arteries to agonists that activate eNOS (eg., ACh, bradykinin). These results importantly suggest that although eNOS may be activated by ischemia, reperfusion profoundly affects and diminishes NO-mediated vasodilation.

One mechanism by which $\mathrm{I} / \mathrm{R}$ can diminish NO-mediated vasodilation is through uncoupling of eNOS and production of superoxide anion instead. A critical determinant of eNOS activity and its ability to produce $\mathrm{NO}$ vs. superoxide is the availability of the cofactor $\mathrm{BH}_{4}$ [77]. Under conditions of limited $\mathrm{BH}_{4}$ availability, eNOS functions in an uncoupled state and the electrons derived from adenine dinucleotide phosphate hydrogen $(\mathrm{NAD}(\mathrm{P}) \mathrm{H})$ are added to molecular oxygen instead of L-arginine, leading to the production of superoxide [78]. Thus, it is possible that eNOS becomes uncoupled during I/R by cofactor depletion because of its enhanced activity in the ischemic brain that uses all available $\mathrm{BH}_{4}$ (ie., substrate depletion). In addition to substrate and cofactor depletion during ischemia, eNOS can become uncoupled through oxidation and inactivation of $\mathrm{BH}_{4}$ during reperfusion. The restoration of blood flow following ischemia causes a significant increase in production of $\mathrm{ONOO}^{-}$[79]. ONOO- is highly cell permeable where it causes cell damage and nitrosylation of proteins and nucleic acids [79]. $\mathrm{ONOO}^{-}$readily produces oxidation of $\mathrm{BH}_{4}$ and may also be an underlying mechanism by which eNOS is uncoupled during I/R [80,81].

The activity of eNOS is also regulated by phosphorylation on specific amino acid residues that may be affected by $\mathrm{I} / \mathrm{R}[82,83]$. NO production is increased following Ser1177 phosphorylation but inhibited by Thr495 phosphorylation [82,83]. Global forebrain ischemia for 10 minutes and 30 minutes of reperfusion caused de-phosphorylation of Thr495 [84]. In this study, Ser1177 phosphorylation was unchanged, but the effect on Thr495 suggests greater eNOS activation. Little is known about how focal ischemia affects the phosphorylation state of eNOS, but may be an important therapeutic target to restore eNOS function.

eNOS phosphorylation has also been shown to regulate superoxide production during eNOS uncoupling [85]. Under conditions of substrate depletion, phosphorylation of Ser1177 increased superoxide generation by eNOS $>50 \%$ and altered the calcium sensitivity of the enzyme such that superoxide production was largely calciumindependent [85]. Thus, during I/R, the altered phosphorylation state of eNOS can both diminish eNOS activity and produce superoxide if the enzyme is uncoupled.

Effect of I/R on EDHF: I/R have been shown to affect EDHF dilation in MCA. Endothelial purinoceptor $\left(\mathrm{P}_{2} \mathrm{Y}_{2}\right)$-mediated dilatations are potentiated following I/R via an upregulation of EDHF responses 
[73]. The basic mechanism by which EDHF-mediated responses are increased during $\mathrm{I} / \mathrm{R}$ is likely through increased intracellular calcium in endothelial cells that activates SK and IK channels causing $\mathrm{K}^{+}$efflux and membrane hyperpolarization [57,73]. However, since EDHF does not contribute to vascular tone of cerebral arteries under basal conditions, it is not likely a prominent target for vascular protection of MCA during I/R. In contrast, penetrating brain arterioles (lenticulostriate) and parenchymal arterioles have been shown to have basal EDHF. Our own study, comparing the effect of I/R on penetrating arterioles, showed that basal tone and EDHF responses are well preserved after I/R. In contrast, constriction to the NOS inhibitor L-NAME was diminished, suggesting that EDHF may be a more robust and persistent vasodilator of penetrating arterioles during I/R [60].

Endothelial cell calcium during I/R: An increase in intracellular calcium $\left(\left[\mathrm{Ca}^{2+}\right]_{\mathrm{i}}\right)$ in endothelial cells is central to many signaling events during I/R [86]. High levels of $\left[\mathrm{Ca}^{2+}\right]_{\mathrm{i}}$ can impair endothelial barrier function [87] and alter activity of enzymes and processes involved in regulation of vascular tone, including eNOS and EDHF. Production of NO by eNOS is principally activated by calcium-dependent binding of calmodulin, making eNOS activation calcium-dependent [88]. During cerebral ischemia when $\left[\mathrm{Ca}^{2+}\right]_{\mathrm{i}}$ remains persistently elevated, eNOS become continuously active and produces potentially toxic amounts of NO [73,89]. Moreover, after 6-12 h of MCA occlusion, cerebral ischemia induces expression of inducible NOS (iNOS) in the vascular cells, which produces large amounts of NO continuously for long periods [90]. Thus, an increase in intracellular calcium in cerebral endothelium is pleiotropic and likely an important therapeutic target during I/R. The mechanism by which $\mathrm{I} / \mathrm{R}$ increase endothelial cell calcium is not known, but may involve RONS-induced activation of SK and IK channels or transient receptor potential (TRP) channels.

Endothelin production during I/R: Endothelin-1 (ET-1) is a potent vasoconstrictor peptide synthesized and released by endothelial cells in cerebral vasculature [91]. ET-1 has a significant role in vascular tone and CBF regulation and is altered during I/R. Marked elevation of ET-1 in plasma, cerebrospinal fluid and ischemic brain has been demonstrated in patients and animal models after ischemic stroke [92-94]. ET-1 regulates vascular tone through the activation of 2 specific receptor subtypes, $\mathrm{ET}_{\mathrm{A}}$ and $\mathrm{ET}_{\mathrm{B}}$ receptors. Under physiological conditions, there is a balance between the vasoconstrictor effect induced by $\mathrm{ET}_{\mathrm{A}}$ receptors on vascular smooth muscle and the vasodilator mechanism mediated by activation of $\mathrm{ET}_{\mathrm{B}}$ receptors on endothelium to produce NO $[95,96] . \mathrm{ET}_{\mathrm{A}}$ receptor antagonists have been shown to improve outcome after experimental cerebral ischemia [97-99]. For example, $\mathrm{ET}_{\mathrm{A}}$ receptor antagonists improved microvascular perfusion [98] and attenuated the increased in brain water and infarct size observed after transient MCAO [99]. In addition, a study using transgenic mice with endothelial ET-1 over-expression showed that $\mathrm{ET}_{\mathrm{A}}$ receptor activation contributes to the increased oxidative stress, water accumulation and BBB breakdown after transient MCAO [100]. Although these studies suggest that activation of $\mathrm{ET}_{\mathrm{A}}$ receptors during $\mathrm{I} / \mathrm{R}$ are detrimental to stroke outcome, the mechanism by which this occurs is not clear. Increased ET-1 during stroke activates superoxide production through $\mathrm{NAD}(\mathrm{P}) \mathrm{H}$ oxidase and increases $\mathrm{BBB}$ permeability, promoting edema [100-102]. In contrast to the role of $\mathrm{ET}_{\mathrm{A}}$ receptor, $\mathrm{ET}_{\mathrm{B}}$ receptors, primarily expressed in endothelial cells, may have a protective role in ET-1 provoked cerebral ischemic injury as $\mathrm{ET}_{\mathrm{B}}$ blockade increased infarct volume after transient MCAO [100].

\section{Collateral flow during $\mathbf{I} / \mathrm{R}$}

The collateral circulation in the brain is the network of arteries and arterioles that maintain and stabilize $\mathrm{CBF}$ when the principal routes of blood flow are occluded or compromised. The collateral blood supply to a brain region will maintain normal CBF during an occlusion initially, after which mechanisms in response to hypoxia/ischemia are invoked that increase flow. If recanalization does not occur rapidly and ischemia is prolonged, oxygen demands by the brain tissue cannot be met and ischemic brain damage occurs. Primary and secondary collateral pathways exist in the brain defined by differences in their conductances and contribution to vascular resistance. Primary collaterals are the arterial segments of the circle of Willis that are responsible for redistribution of blood flow when extracranial or large intracranial vessels are occluded [103,104]. These arteries form a low-resistance anastomotic loop that provides collateral support to the anterior and posterior circulations. Being low resistance, the primary collaterals provide immediate redistribution of $\mathrm{CBF}$ to ischemic regions through existing anastomoses. Leptomenigeal anastomoses are secondary collateral vessels that redistribute $\mathrm{CBF}$ when occlusion occurs distal to the circle of Willis [104]. These pial vessels are high-resistance distal anastomoses between vascular territories and determine perfusion pressure and the severity of ischemia after distal occlusion to the circle of Willis. Because the leptomeningeal arterioles are high-resistance vessels, recruitment of flow by secondary collaterals involves invoking vasodilatory mechanisms and is slower than recruitment of primary collaterals [103,104].

Both the caliber and number of primary and secondary collateral vessels determine the degree of collateral supply and therefore the severity of ischemia. Overall, the collateral circulation critically establishes perfusion pressure during ischemia and maintains perfusion to the penumbra $[105,106]$. Structural remodeling of these vessels is also an important determinant of collateral flow because it influences their caliber. Outward hypotrophic remodeling (increased inner diameter with decreased cross sectional area of the wall), occurs when there is chronic hypoperfusion of upstream vessels that alters shear stress distally (eg., carotid stenosis, atherosclerosis). Inward hypertrophic remodeling (reduced inner diameter and increased cross sectional area of the wall) can occur during pathological states such as hypertension. Structural remodeling will ultimately determine the size of the collaterals and thus hemodynamic reserve capacity when maximally dilated during hypoxia/ischemia. Therefore, interventions that actively dilate collaterals as well as promote outward remodeling may be important therapeutic targets for increasing flow to the penumbra and limiting stroke damage.

\section{The penumbra}

Reperfusion after focal brain ischemia is generally thought to be beneficial, however, the window of opportunity for improvement of stroke outcome is brief ( $<6$ hours), after which reperfusion is no longer beneficial $[103,107]$. One target of reperfusion is the ischemic penumbra, a region of constrained blood supply in which energy metabolism is preserved [108]. The penumbra in the ischemic brain is of considerable interest to stroke therapy because it is a region in which neurons are electrically silent (cannot fire action potentials), but retain a $-70 \mathrm{mV}$ membrane potential [109]. Unfortunately, this region is also the basis for progressive evolution of ischemic injury, ie., the infarct expands to include the penumbra [110,111]. Many neuroprotective strategies have been employed to limit expansion of infarcted tissue into the penumbra with little success. However, the role of the collateral 
vessels in evolving infarction is critical and may provide an important therapeutic target to salvage the penumbra. Recently, the concept of the penumbra has been expanded to include repair mechanisms that begin concurrent with stroke damage [112]. Thus, inhibiting only damaging processes during stroke treatment may only target half the problem or in some cases be harmful. This concept of repair and damage occurring simultaneously is probably true for the vasculature as well although repair is largely understudied in vascular protection.

\section{Parenchymal arterioles during I/R}

Penetrating arteries branch at right angles off the pial arteries and lie within the Virchow-Robin space. The penetrating arteries turn into parenchymal arterioles once they penetrate into the brain tissue where they become surrounded by astrocytic end feet and are innervated intrinsically from within the brain tissue [113-115]. Parenchymal arterioles have greater basal tone at lower pressures than upstream pial arteries [115]. Because of their considerable basal tone, they contribute approximately $40 \%$ to CVR. While pial vessels are anatomically networked such that occlusion of one surface vessel does not appreciably decrease CBF [116], penetrating and parenchymal arterioles are long and largely unbranched vessels that are not interconnected and as such occlusion of an individual arteriole results in significant reductions in flow and damage to surrounding brain tissue (infarction) [116]. These vessels have been shown to be a bottleneck for blood flow to the microcirculation, the occlusion of which allows little if any collateral flow due to their unbranched architecture [116]. Penetrating and parenchymal arterioles are part of the neurovascular unit and are functionally distinct from the larger MCA. In addition to possessing greater basal tone than upstream arteries, they also have larger influence of EDHF on tone and are largely unresponsive to neurotransmitters such as norepinephine and serotonin $[60,115,117]$. Another significant difference between MCA and parenchymal arterioles is their response to I/R. Similar to peripheral organ vasculature, pial arteries dilate to hypoxic conditions, however, parenchymal arterioles appear to lack this response $[8,60,118]$. Thus, parenchymal arterioles maintain significant vascular tone during $\mathrm{I} / \mathrm{R}$ and therefore likely contribute to perfusion deficit and expansion of infarct into the penumbra.

\section{Microcirculation during I/R}

The cerebral capillary bed comprises a unique endothelium compared to endothelium outside the central nervous system (CNS) and is the site of the $\mathrm{BBB}$. Its unique features are highly protective of the brain milieu and include continuous, high electrical resistance tight junctions that restrict ion flux, limited transcellular transport, very low hydraulic conductivity and a large number of mitochondrion [119]. In addition, the cerebral microcirculation is in close association with other cell types within the brain, including astrocytes, pericytes and neurons separated by the basal lamina, a specialized extracellular matrix generated by both endothelial cells and astrocytes [120,121]. Together, the cellular and acellular components of the cerebral microcirculation comprise a "neurovascular unit" that is an important therapeutic target in stroke [122]. During ischemic stroke, microvessel integrity is compromised, an event that has far-reaching implications for outcome and recovery. Experimental animal models have shown that despite recanalization of an occluded artery, the microcirculation can limit tissue perfusion due to several mechanisms that occlude capillaries, including plugging with cellular elements of blood and fibrin, pericyte contraction and cytotoxic edema of endothelial cell and astrocyte endfeet [123-127]. Microcirculatory obstruction is implicated in the non-reflow phenomenon after reperfusion and negatively affects tissue survival by limiting substrate and therapeutic agents, such as neuroprotectants, from reaching their target.

Cytotoxic edema results from influx of cations (sodium), into the cell through cation channels. Nonselective cation (NC) channels are important mediators of cell swelling because they allow flux of any monovalent cation to pass [128]. One of the most important NC channels in ischemic stroke is the $\mathrm{NC}_{\mathrm{Ca}-\mathrm{ATP}}$ channel. This channel is not constitutively expressed, but is induced during focal ischemia in astrocytes, neurons and endothelium [129]. Inhibitors of the regulatory subunit of $\mathrm{NC}_{\text {Ca-ATP }}$ channel, SUR1, prevent cytotoxic edema and improve stroke outcome [129]. As ischemia progresses, vasogenic edema and hemorrhagic transformation also occur due to microvascular disturbances [120-122,130]. Thus, preserving microvascular structure and function during $\mathrm{I} / \mathrm{R}$ is an important target for stroke therapy.

There are several processes that occur during I/R that specifically affect the neurovascular unit. The hypoxic tissue activates microglia, astrocytes and endothelial cells that produce cytokines, chemokines and matrix metalloproteinases (MMP) [131,132]. Upregulation of cell adhesion molecules by vascular endothelial cells promote infiltration of leukocytes into the brain that can also secrete cytokines and produce RONS [44,130-132]. In addition, cytokines can induce expression of several enzymes such as iNOS and cyclooxygenase (COX) that amplify the inflammatory response [133]. Thus, post-ischemic inflammatory processes cause microvascular dysfunction that can significantly exacerbate damage to the ischemic penumbra $[131,132]$. In addition, inflammatory cytokines produced by the ischemic brain can also affect BBB integrity and exacerbate edema formation [134]. BBB disruption can also result from the increased expression and activation of MMPs during ischemia that is increased by pro-inflammatory cytokines such as tumor necrosis factor $\forall(\mathrm{TNF} \forall)$ [135]. In addition to proinflammatory cytokines, other circulating factors are released during $\mathrm{I} / \mathrm{R}$ that increase $\mathrm{BBB}$ permeability and promote vasogenic edema formation, including vascular endothelial growth factor (VEGF), histamine and thrombin [119].

\section{Hyperglycemia during $I / R$}

Hyperglycemia is common in acute stroke, affecting up to $40 \%$ of ischemic stroke patients, often without a preexisting diagnosis of diabetes [136]. Hyperglycemia during stroke can be caused by several effects, including a generalized stress response to acute brain injury and impaired glucose tolerance, but may also be the first presentation of previously unrecognized diabetes [137-139]. Hyperglycemia during acute stroke is associated with significantly worsened outcome, including larger infarction, edema formation and a higher risk of mortality $[140,141]$. The exacerbated damage with hyperglycemia is especially prevalent in transient ischemic stroke models and occurs less with permanent occlusion [142], suggesting reperfusion may be an important factor in hyperglycemic brain injury.

Hyperglycemia alters vascular responses and can exacerbate ischemic brain damage through multiple mechanisms including acidosis, vascular inflammation, increased BBB permeability, hemorrhagic transformation, accumulation of free radicals and impaired vascular reactivity [143]. The mechanisms by which hyperglycemia exacerbates ischemic damage has been extensively studied. Extracellular hyperglycemia activates Glut-1 transporters in cerebral endothelial cells that cause endothelial intracellular hyperglycemia [144]. Intracellular hyperglycemia can induce a variety of detrimental changes in vascular cells within hours $[145,146]$. 
Citation: Palomares SM, Cipolla MJ (2011) Vascular Protection Following Cerebral Ischemia and Reperfusion. J Neurol Neurophysiol S1. doi:10.4172/2155-9562.S1-004

For example, it can decrease $\mathrm{NAD}(\mathrm{P}) \mathrm{H}$-production, an important intracellular antioxidant. Intracellular high glucose can also induce posttranslational modifications of proteins via the hexosamine pathway and activate protein kinase $\mathrm{C}$ (PKC) that increases RONS via $\mathrm{NAD}(\mathrm{P}) \mathrm{H}$ oxidase, stimulates pro-inflammatory gene expression and impairs NO-mediated vasodilation. Hyperglycemia also causes eNOS dysfunction and enhanced plasminogen activator inhibitor-1 (PAI-1) expression causing thrombus stabilization and microvascular plugging (for review see 138). All these pro-inflammatory, pro-thrombotic and pro-vasoconstrictive mechanisms activate in response to intracellular hyperglycemia and can have significant effects on vascular function to impair reperfusion $[142,147,148]$.

One of the most detrimental consequences of hyperglycemic stroke is the development of brain edema during reperfusion [149].
Experimental studies have shown that hyperglycemia causes edema formation after cerebral ischemia that is more pronounced than in normoglycemic animals [140,150,151]. Increased BBB permeability occurs during hyperglycemic stroke and causes cerebral edema $[150,152,153]$. Different mechanisms have been implicated in BBB dysfunction after hyperglycemic I/R injury, including increased oxidative stress, MMP activation, enhanced lactic acidosis and increased PKC activation [150,151,153]. Both MMP production and PKC activation are important therapeutic targets to limit BBB damage during hyperglycemic focal ischemia. For example MMPs, particularly MMP-9, can degrade components of the extracellular matrix around the blood vessels causing proteolytic degradation of the BBB after cerebral ischemia [153]. PKC activation by hyperglycemia can directly affect BBB permeability through its ability to phosphorylate zona occluden-1

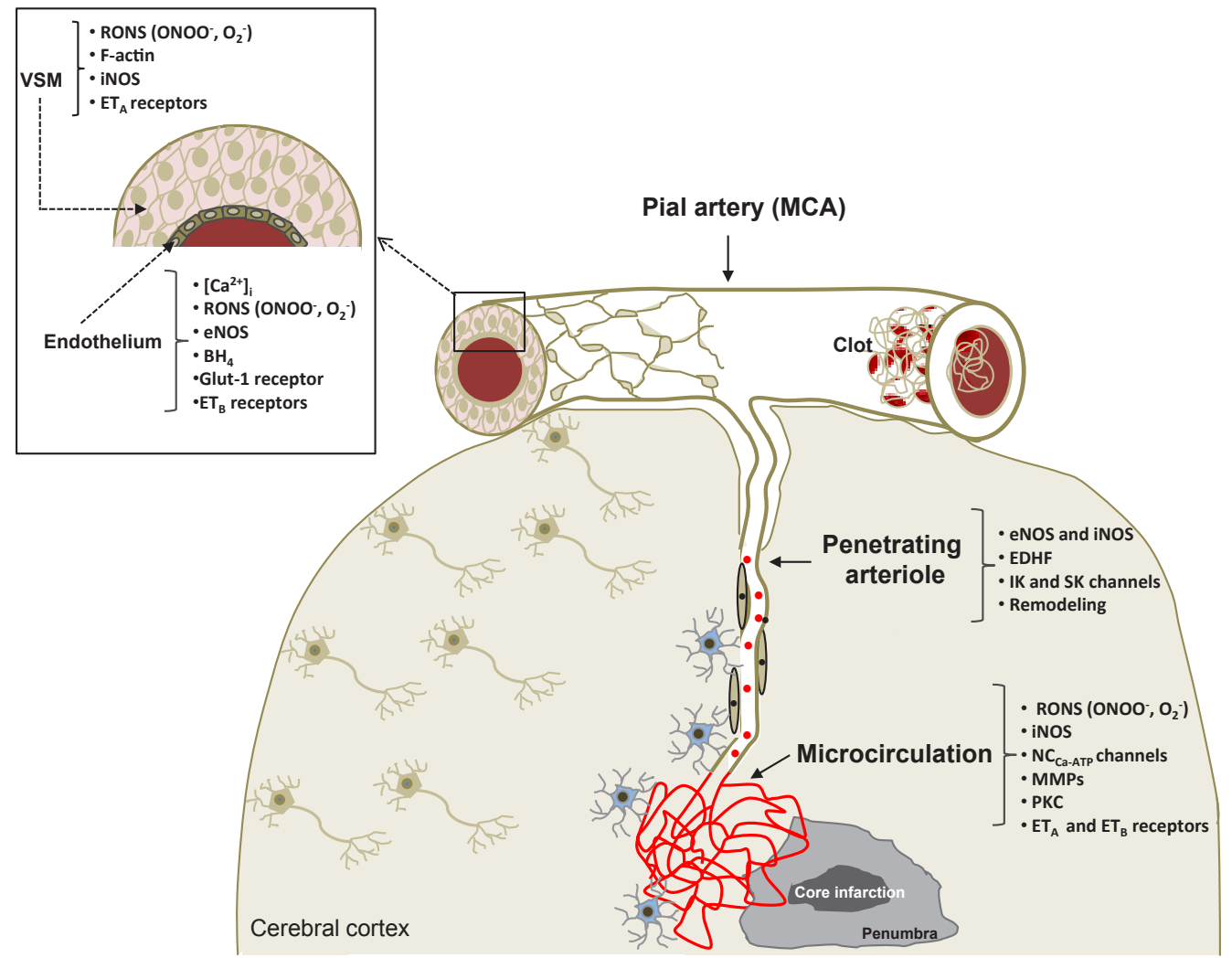

Figure 4: Important targets for vascular protection during cerebral I/R.

Some of the molecules present in different cerebral vascular segments that are involved in vascular dysfunction during $\mathrm{I} / \mathrm{R}$ and may be important targets for vascular protection. At the level of MCA, I/R affect endothelial cells through an increase in $\left[\mathrm{Ca}^{2+}\right]_{i}$. High calcium levels alter activity of enzymes such as eNOS which produces potentially toxic amounts of NO. The excess of $\mathrm{NO}$ combines with others RONS such as $\mathrm{O}_{2}^{-}$to form ONOO-, which decreases the effectiveness of $\mathrm{NO}^{-}$and interacts with lipids, DNA and proteins causing cell dysfunction and death. eNOS activity is also affected by limited availability and oxidation of the cofactor $\mathrm{BH}_{4}$ and by changes in its phosphorylation state. In addition, extracellular hyperglycemia activates Glut-1 transporters, causing endothelial intracellular hyperglycemia which induces a variety of detrimental changes in vascular cerebral cells. In contrast, activation of ET receptor by an increase in ET-1 production during I/R may have a protective role in cerebral ischemic injury. In VSM, I/R cause increased RONS that damages important structures, including the actin cytoskeleton. ONOO- causes nitrosylation of F-actin and loss of myogenic tone. This pathological mechanism is fed by increased expression of iNOS that produces large amounts of NO for long periods and by $\mathrm{ET}_{\mathrm{A}}$ receptor activation that increases oxidative stress. At the level of penetrating arterioles the signaling molecules that play an important role in vascular function are eNOS, iNOS, EDHF and SK and IK channels. Penetrating arterioles have considerable basal tone despite I/R and this likely contributed to expansion of the infarct into the penumbra. Thus, remodeling of penetrating arterioles to increase lumen diameter may also be highly protective of the penumbra. Finally, postischemic inflammatory processes and RONS production, that are enhanced by iNOS activity, can also compromise the microcirculation. These effects on the microcirculation can significantly exacerbate damage to the ischemic penumbra. An important mediator of stroke outcome is the nonselective cation channel $\mathrm{NC}_{\mathrm{CaATP}}$ which is involved in cytotoxic edema. In addition, expression and activation of MMPs, ET receptors and PKC can cause BBB disruption and hemorrhagic transformation. (Abbreviations: [ $\left.\mathrm{Ca}^{2+}\right]_{\text {: }}$ intracellular calcium; eNOS: endothelial nitric oxide synthase; RONS: reactive oxygen and nitrogen species; $\mathrm{O}_{2}:$ superoxide; ONOO: peroxynitrite; $\mathrm{BH}_{4}$ : tetrahydrobiopterin; Glut-1: glucose transporter 1; $\mathrm{ET}_{\mathrm{B}}$ receptor: endothelin-1 receptor type B; VSM: vascular smooth muscle; iNOS: inducible nitric oxide synthase; $\mathrm{ET}_{\mathrm{A}}$ receptor: endothelin-1 receptor type A; EDHF: endothelium-derived hyperpolarizing factor; SK: small-conductance calciumactivated potassium channel; IK: intermediate-conductance calcium-activated potassium channel; $\mathrm{NC}_{\mathrm{Ca}-\mathrm{ATP}}$ : nonselective cation channel regulated by cytoplasmic $\mathrm{Ca}^{2+}$ and ATP; MMPs: matrix metalloproteinases; and PKC: protein kinase C). 
Citation: Palomares SM, Cipolla MJ (2011) Vascular Protection Following Cerebral Ischemia and Reperfusion. J Neurol Neurophysiol S1. doi:10.4172/2155-9562.S1-004

(ZO-1) affecting the integrity of the tight junction as well as can promote calcium/calmodulin-dependent endothelial cell contraction, increasing paracellular permeability $[154,155]$. A recent study showed that inhibition of $\mathrm{PKC} \exists$ reversed increased $\mathrm{BBB}$ permeability during hyperglycemic stroke and was effective at preventing edema formation in vivo when given prior to reperfusion [144].

\section{Inflammation during $\mathbf{I} / \mathbf{R}$}

Inflammation is an important mechanism in the pathogenesis of stroke $[44,131,132,156]$. Production of proinflammatory cytokines and chemokines increases after stroke, including the cytokines tumor necrosis factor- $\alpha$ (TNF- $\alpha$ ), the interleukins (IL) IL-1 $\beta$, IL-6, IL-10, IL20 and transforming growth factor (TGF)- $\beta$, and the chemokines IL-8, interferon inducible protein-10 (IP-10) and monocyte chemoattractant protein-1 (MCP-1) [42,131,157]. IL-1 $\beta$, TNF- $\alpha$, IL-8 and MCP-1 appear to exacerbate ischemic injury, whereas the anti-inflammatory cytokines IL-10, TGF- $\beta$ and IL-1ra appear to be neuroprotective [157]. High levels of pro-inflammatory cytokines and lower levels of antiinflammatory cytokines are associated increased infarction and poorer clinical outcome. Inflammation therefore becomes an important target to limit ischemic tissue damage. In fact, some studies have shown that the use of anti-inflammatory agents such as IL-1 receptor antagonist and IL-10 are associated with better stroke outcome [158,159].

Elevated circulating levels of pro-inflammatory cytokines after stroke may affect vascular function, including influencing vascular tone and acting on the endothelial and vascular smooth muscle [160]. Endothelium and vascular smooth muscle express receptors for TNF $\alpha$, IL-1 $\beta$, IL-6 and IL-10 [161,162]. TNFa, IL-1 $\beta$ and IL-6 can cause vasoconstriction, increased vasoconstrictor responses, and impaired endothelium-dependent vasodilatation [163]. Injection of TNFa into the cisterna magna reduces cerebral blood flow in the rabbit, demonstrating that this cytokine can affect perfusion [164]. The underlying mechanism by which inflammatory cytokines affect vascular tone is not well-understood, but may involve cytokineinduced RONS production. TNF $\alpha$ can stimulate RONS production in endothelium by activating oxidative enzymes including COX, xanthine oxidase and $\mathrm{NAD}(\mathrm{P}) \mathrm{H}$ oxidase [165]. In addition, cytokines may also increase iNOS expression in vascular smooth muscle and endothelial cells, which produces an excess of NO that can impair vasomotor responses and react with superoxide to produce ONOO- $[54,163]$.

A systemic effect of stroke has been shown in studies that found impaired endothelium-dependent vasodilation in cerebral and brachial arteries in stroke patients, suggesting that both cerebral and peripheral endothelial function is affected by a systemic reaction in response to cerebral ischemia [166-168]. The role of circulating inflammatory mediators in brain vascular dysfunction and secondary brain injury is largely understudied, but may be an important target for vascular protection during stroke. Recently, we studied the effect of plasma from hyperglycemic animals that underwent MCA occlusion (MCAO) on vascular function. We found that circulating factors present in plasma during postischemic reperfusion increased myogenic tone and impaired endothelial function in nonischemic MCA [169].

\section{Conclusions and Future Directions}

The successful development of targeted therapies for stroke likely requires vascular protection as well as neuroprotection. Thus, an understanding of the mechanisms by which $\mathrm{I} / \mathrm{R}$ affect the cerebral circulation would be beneficial to stroke treatment. Because I/R affect different vascular segments in the brain, including pial arteries, parenchymal arterioles and the microcirculation that control both the extent of ischemia and the degree of reperfusion, they are all potential targets for vascular protection. After I/R, arteries such as MCA have loss of myogenic tone and vascular paralysis can that impair autoregulation and promote loss of control of CBF that exacerbates ischemic injury. Ischemic brain injury is likely worsened by parenchymal arterioles that still have considerable basal tone during $\mathrm{I} / \mathrm{R}$, acting as a bottleneck to flow to the microcirculation. Microvascular function is also affected by $\mathrm{I} / \mathrm{R}$, causing cytotoxic edema and BBB disruption that can cause edema and hemorrhage, thus contributing to poor outcome after stroke. Finally, inflammatory processes and RONS production during postischemic reperfusion, that are more intense under hyperglycemic conditions, also impair vascular function and may also be targets for vascular protection and treatment of secondary brain injury. Figure 4 summarizes some potentially important molecules and pathways that are therapeutic targets to protect the vasculature during stroke.

There are several potential therapeutic targets for vascular protection, however, the translation of these preclinical results into therapies that improve ischemic stroke outcome is still important. Combined therapies that include vascular protective agents as well as neural protective agents may enable development of more effective stroke treatment. This approach may be superior to single treatment because it would maintain the supply of necessary nutrients and neuroprotective agents to the brain tissue a risk, while effectively removing waste and cellular debris. In addition, because of the importance of the high resistance collateral circulation in the pathophysiology of stroke, targeted therapies that selectively dilate intraparenchymal arterioles during reperfusion may prove useful to salvaging the penumbra and preventing expansion of the infarct.

\section{Acknowledgements}

We gratefully acknowledge the continued support of the NIH, NINDS grants RO1 NS043316, NS045940, The Neural Environment Cluster supplement 3RO1 NS045940-06S1, ARRA supplement 3RO1 NS045940-05S1, NHLBI grant PO1 HL095488 and the Totman Medical Research Trust.

\section{References}

1. Nishigaya K, Yoshida Y, Sasuga M, Nukui H, Ooneda G (1991) Effect of recirculation on exacerbation of ischemic vascular lesions in rat brain. Stroke 22: $635-642$

2. Cipolla MJ, McCall AL, Lessov N, Porter JM (1997) Reperfusion decreases myogenic reactivity and alters middle cerebral artery function after focal cerebral ischemia in rats. Stroke 28: 176-180.

3. Kagstrom E, Smith ML, Siesjo BK (1983) Local cerebral blood flow in the recovery period following complete cerebral ischemia in the rat. J Cereb Blood Flow Metab 3: 170-182.

4. Takahashi A, Park HK, Melgar MA, Alcocer L, Pinto J, et al. (1997) Cerebra cortex blood flow and vascular smooth muscle contractility in a rat model of ischemia: a correlative laser Doppler flowmetric and scanning electron microscopic study. Acta Neuropathol 93: 354-368.

5. Siesjo BK (1992) Pathophysiology and treatment of focal cerebral ischemia. Part II: Mechanisms of damage and treatment. J Neurosurg 77: 337-354.

6. Siesjo BK (1992) Pathophysiology and treatment of focal cerebral ischemia Part I: Pathophysiology. J Neurosurg 77: 169-184.

7. Tasdemiroglu E, Macfarlane R, Wei EP, Kontos HA, Moskowitz MA (1992) Pia vessel caliber and cerebral blood flow become dissociated during ischemiareperfusion in cats. Am J Physiol 263: H533-536.

8. Cipolla MJ, Bullinger LV (2008) Reactivity of brain parenchymal arterioles after ischemia and reperfusion. Microcirculation 15: 495-501.

9. Phillips SJ, Whisnant JP (1992) Hypertension and the brain. The National High Blood Pressure Education Program. Arch Intern Med 152: 938-945. 
Citation: Palomares SM, Cipolla MJ (2011) Vascular Protection Following Cerebral Ischemia and Reperfusion. J Neurol Neurophysiol S1. doi:10.4172/2155-9562.S1-004

10. Faraci FM, Baumbach GL, Heistad DD (1989) Myogenic mechanisms in the cerebral circulation. J Hypertens Suppl 7: S61-64.

11. Olsen TS, Larsen B, Skriver EB, Herning M, Enevoldsen E, et al. (1981) Focal cerebral hyperemia in acute stroke. Incidence, pathophysiology and clinical significance. Stroke 12: 598-607.

12. Lassen NA, Agnoli A (1972) The upper limit of autoregulation of cerebral blood flow--on the pathogenesis of hypertensive encepholopathy. Scand J Clin Lab Invest 30: 113-116.

13. Euser AG, Cipolla MJ (2007) Cerebral blood flow autoregulation and edema formation during pregnancy in anesthetized rats. Hypertension 49: 334-340.

14. Johansson B, Li CL, Olsson Y, Klatzo I (1970) The effect of acute arterial hypertension on the blood-brain barrier to protein tracers. Acta Neuropathol 16: $117-124$

15. Gourley JK, Heistad DD (1984) Characteristics of reactive hyperemia in the cerebral circulation. Am J Physiol 246: H52-58.

16. Sundt TM, Waltz AG (1971) Cerebral ischemia and reactive hyperemia. Studies of cortical blood flow and microcirculation before, during, and after temporary occlusion of middle cerebral artery of squirrel monkeys. Circ Res 28: 426-433.

17. Hayakawa T, Waltz AG, Hansen T (1977) Relationships among intracranial pressure, blood pressure, and superficial cerebral vasculature after experimental occlusion of one middle cerebral artery. Stroke 8: 426-432.

18. Skinhoj E, Hoedt-Rasmussen K, Paulson OB, Lassen NA (1970) Regiona cerebral blood flow and its autoregulation in patients with transient focal cerebral ischemic attacks. Neurology 20: 485-493.

19. Macfarlane R, Moskowitz MA, Sakas DE, Tasdemiroglu E, Wei EP, et al. (1991) The role of neuroeffector mechanisms in cerebral hyperperfusion syndromes. J Neurosurg 75: 845-855.

20. Paulson OB, Strandgaard S, Edvinsson L (1990) Cerebral autoregulation. Cerebrovasc Brain Metab Rev 2: 161-192.

21. Shapiro HM, Stromberg DD, Lee DR, Wiederhielm CA (1971) Dynamic pressures in the pial arterial microcirculation. Am J Physiol 221: 279-283.

22. Faraci FM, Heistad DD (1990) Regulation of large cerebral arteries and cerebra microvascular pressure. Circ Res 66: 8-17

23. Mellander S (1989) Functional aspects of myogenic vascular control. J Hypertens Suppl 7: S21-30.

24. Johansson B (1989) Myogenic tone and reactivity: definitions based on muscle physiology. J Hypertens Suppl 7: S5-8.

25. Osol G, Brekke JF, McElroy-Yaggy K, Gokina NI (2002) Myogenic tone reactivity, and forced dilatation: a three-phase model of in vitro arterial myogenic behavior. Am J Physiol Heart Circ Physiol 283: H2260-2267.

26. Kontos HA, Wei EP, Navari RM, Levasseur JE, Rosenblum WI, et al. (1978) Responses of cerebral arteries and arterioles to acute hypotension and hypertension. Am J Physiol 234: H371-383.

27. Cipolla MJ, Lessov N, Hammer ES, Curry AB (2001) Threshold duration of ischemia for myogenic tone in middle cerebral arteries: effect on vascular smooth muscle actin. Stroke 32: 1658-1664.

28. Cipolla MJ, Curry AB (2002) Middle cerebral artery function after stroke: the threshold duration of reperfusion for myogenic activity. Stroke 33: 2094-2099.

29. Yamaguchi T, Waltz AG, Okazaki H (1971) Hyperemia and ischemia in experimental cerebral infarction: correlation of histopathology and regional blood flow. Neurology 21: 565-578.

30. Olsen TS (1986) Regional cerebral blood flow after occlusion of the middle cerebral artery. Acta Neurol Scand 73: 321-337.

31. Cipolla MJ, Gokina NI, Osol G (2002) Pressure-induced actin polymerization in vascular smooth muscle as a mechanism underlying myogenic behavior. FASEB J 16: 72-76.

32. Cipolla MJ, Osol G (1998) Vascular smooth muscle actin cytoskeleton in cerebral artery forced dilatation. Stroke 29: 1223-1228.
33. Banan A, Fields JZ, Zhang Y, Keshavarzian A (2001) iNOS upregulation mediates oxidant-induced disruption of $\mathrm{F}$-actin and barrier of intestina monolayers. Am J Physiol Gastrointest Liver Physiol 280: G1234-1246.

34. Schwartz N, Hosford M, Sandoval RM, Wagner MC, Atkinson SJ, et al. (1999) Ischemia activates actin depolymerizing factor: role in proximal tubule microvillar actin alterations. Am J Physiol 276: F544-551.

35. Hsu SS, Meno JR, Gronka R, Kushmerick M, Winn HR (1994) Moderate hyperglycemia affects ischemic brain ATP levels but not intracellular $\mathrm{pH}$. Am J Physiol 266: H258-262.

36. Gisselsson LL, Matus A, Wieloch T (2005) Actin redistribution underlies the sparing effect of mild hypothermia on dendritic spine morphology after in vitro ischemia. J Cereb Blood Flow Metab 25: 1346-1355.

37. Pacher $P$, Beckman JS, Liaudet $L$ (2007) Nitric oxide and peroxynitrite in health and disease. Physiol Rev 87: 315-424.

38. Bemeur C, Ste-Marie L, Montgomery J (2007) Increased oxidative stress during hyperglycemic cerebral ischemia. Neurochem Int 50: 890-904.

39. Maneen MJ, Hannah R, Vitullo L, DeLance N, Cipolla MJ (2006) Peroxynitrite diminishes myogenic activity and is associated with decreased vascular smooth muscle F-actin in rat posterior cerebral arteries. Stroke 37: 894-899.

40. ladecola C (1997) Bright and dark sides of nitric oxide in ischemic brain injury. Trends Neurosci 20: 132-139.

41. Wei EP, Kontos HA, Beckman JS (1996) Mechanisms of cerebral vasodilation by superoxide, hydrogen peroxide, and peroxynitrite. Am J Physiol 271: H12621266.

42. Offner $\mathrm{H}$, Subramanian S, Parker SM, Afentoulis ME, Vandenbark AA, et al (2006) Experimental stroke induces massive, rapid activation of the periphera immune system. J Cereb Blood Flow Metab 26: 654-665

43. Shreeniwas R, Koga S, Karakurum M, Pinsky D, Kaiser E, et al. (1992) Hypoxia-mediated induction of endothelial cell interleukin-1 alpha. An autocrine mechanism promoting expression of leukocyte adhesion molecules on the vessel surface. J Clin Invest 90: 2333-2339.

44. Wang CX, Shuaib A (2002) Involvement of inflammatory cytokines in central nervous system injury. Prog Neurobiol 67: 161-172.

45. Maneen MJ, Cipolla MJ (2007) Peroxynitrite diminishes myogenic tone in cerebral arteries: role of nitrotyrosine and F-actin. Am J Physiol Heart Circ Physiol 292: H1042-1050.

46. Li J, Li W, Altura BT, Altura BM (2005) Peroxynitrite-induced relaxation in isolated rat aortic rings and mechanisms of action. Toxicol Appl Pharmacol 209: 269-276.

47. Cohen RA, Adachi T (2006) Nitric-oxide-induced vasodilatation: regulation by physiologic s-glutathiolation and pathologic oxidation of the sarcoplasmic endoplasmic reticulum calcium ATPase. Trends Cardiovasc Med 16: 109-114.

48. Kunz A, Park L, Abe T, Gallo EF, Anrather J, et al. (2007) Neurovascula protection by ischemic tolerance: role of nitric oxide and reactive oxygen species. J Neurosci 27: 7083-7093.

49. Kleindorfer D, Xu Y, Moomaw CJ, Khatri P, Adeoye O, et al. (2009) US geographic distribution of rt-PA utilization by hospital for acute ischemic stroke. Stroke 40: 3580-3584.

50. Koudstaal PJ, Stibbe J, Vermeulen M (1988) Fatal ischaemic brain oedema after early thrombolysis with tissue plasminogen activator in acute stroke. BMJ 297: 1571-1574

51. Cipolla MJ, Lessov N, Clark WM, Haley EC (2000) Postischemic attenuation of cerebral artery reactivity is increased in the presence of tissue plasminogen activator. Stroke 31: 940-945.

52. Andresen J, Shafi NI, Bryan RM (2006) Endothelial influences on cerebrovascular tone. J Appl Physiol 100: 318-327.

53. Faraci FM (2011) Protecting against vascular disease in brain. Am J Physio Heart Circ Physiol 300: H1566-1582.

54. Faraci FM, Brian JE (1994) Nitric oxide and the cerebral circulation. Stroke 25 692-703. 
Citation: Palomares SM, Cipolla MJ (2011) Vascular Protection Following Cerebral Ischemia and Reperfusion. J Neurol Neurophysiol S1. doi:10.4172/2155-9562.S1-004

55. Marrelli SP, Eckmann MS, Hunte MS (2003) Role of endothelial intermediate conductance KCa channels in cerebral EDHF-mediated dilations. Am J Physiol Heart Circ Physiol 285: H1590-1599.

56. McNeish AJ, Sandow SL, Neylon CB, Chen MX, Dora KA, et al. (2006) Evidence for involvement of both IKCa and SKCa channels in hyperpolarizing responses of the rat middle cerebral artery. Stroke 37: 1277-1282.

57. Dora KA, Gallagher NT, McNeish A, Garland CJ (2008) Modulation of endothelial cell KCa3.1 channels during endothelium-derived hyperpolarizing factor signaling in mesenteric resistance arteries. Circ Res 102: 1247-1255.

58. Zygmunt PM, Hogestatt ED (1996) Role of potassium channels in endotheliumdependent relaxation resistant to nitroarginine in the rat hepatic artery. $\mathrm{Br} \mathrm{J}$ Pharmacol 117: 1600-1606.

59. Si H, Heyken WT, Wolfle SE, Tysiac M, Schubert R, et al. (2006) Impaired endothelium-derived hyperpolarizing factor-mediated dilations and increased blood pressure in mice deficient of the intermediate-conductance $\mathrm{Ca}^{2+}$-activated $\mathrm{K}^{+}$channel. Circ Res 99: 537-544.

60. Cipolla MJ, Smith J, Kohlmeyer MM, Godfrey JA (2009) SKCa and IKCa Channels, myogenic tone, and vasodilator responses in middle cerebral arteries and parenchymal arterioles: effect of ischemia and reperfusion. Stroke 40: 1451-1457.

61. Ledoux J, Werner ME, Brayden JE, Nelson MT (2006) Calcium-activated potassium channels and the regulation of vascular tone. Physiology (Bethesda) 21: $69-78$.

62. Dalkara T, Moskowitz MA (1994) The complex role of nitric oxide in the pathophysiology of focal cerebral ischemia. Brain Pathol 4: 49-57.

63. Lo EH, Hara H, Rogowska J, Trocha M, Pierce AR, et al. (1996) Temporal correlation mapping analysis of the hemodynamic penumbra in mutant mice deficient in endothelial nitric oxide synthase gene expression. Stroke 27: 1381 1385 .

64. Huang Z, Huang PL, Ma J, Meng W, Ayata C, et al. (1996) Enlarged infarcts in endothelial nitric oxide synthase knockout mice are attenuated by nitro-Larginine. J Cereb Blood Flow Metab 16: 981-987

65. Panahian N, Yoshida T, Huang PL, Hedley-Whyte ET, Dalkara T, et al. (1996) Attenuated hippocampal damage after global cerebral ischemia in mice mutant in neuronal nitric oxide synthase. Neuroscience 72: 343-354.

66. Zhang ZG, Chopp M, Bailey F, Malinski T (1995) Nitric oxide changes in the rat brain after transient middle cerebral artery occlusion. J Neurol Sci 128: 22-27.

67. ladecola C (1993) Regulation of the cerebral microcirculation during neural activity: is nitric oxide the missing link? Trends Neurosci 16: 206-214.

68. Kanwar S, Kubes P (1995) Nitric oxide is an antiadhesive molecule for leukocytes. New Horiz 3: 93-104.

69. Szabo C (1996) The pathophysiological role of peroxynitrite in shock, inflammation, and ischemia-reperfusion injury. Shock 6: 79-88.

70. Heinzel B, John M, Klatt P, Bohme E, Mayer B (1992) $\mathrm{Ca}^{2+} /$ calmodulindependent formation of hydrogen peroxide by brain nitric oxide synthase. Biochem J 281: 627-630.

71. Pou S, Pou WS, Bredt DS, Snyder SH, Rosen GM (1992) Generation of superoxide by purified brain nitric oxide synthase. J Biol Chem 267: 2417324176.

72. Veltkamp R, Rajapakse N, Robins G, Puskar M, Shimizu K, et al. (2002) Transient focal ischemia increases endothelial nitric oxide synthase in cerebral blood vessels. Stroke 33: 2704-2710.

73. Marrelli SP, Khorovets A, Johnson TD, Childres WF, Bryan RM (1999) P2 purinoceptor-mediated dilations in the rat middle cerebral artery after ischemiareperfusion. Am J Physiol 276: H33-41.

74. Mayhan WG, Amundsen SM, Faraci FM, Heistad DD (1988) Responses of cerebral arteries after ischemia and reperfusion in cats. Am J Physiol 255: H879-884.

75. Rosenblum WI (1997) Selective impairment of response to acetylcholine after ischemia/reperfusion in mice. Stroke 28: 448-451.
76. Nelson CW, Wei EP, Povlishock JT, Kontos HA, Moskowitz MA (1992) Oxygen radicals in cerebral ischemia. Am J Physiol 263: H1356-1362.

77. Tayeh MA, Marletta MA (1989) Macrophage oxidation of L-arginine to nitric oxide, nitrite, and nitrate. Tetrahydrobiopterin is required as a cofactor. $\mathrm{J}$ Bio Chem 264: 19654-19658

78. Xia Y, Tsai AL, Berka V, Zweier JL (1998) Superoxide generation from endothelial nitric-oxide synthase. A $\mathrm{Ca}^{2+} /$ calmodulin-dependent and tetrahydrobiopterin regulatory process. J Biol Chem 273: 25804-25808.

79. Beckman JS, Chen J, Crow JP, Ye YZ (1994) Reactions of nitric oxide superoxide and peroxynitrite with superoxide dismutase in neurodegeneration. Prog Brain Res 103: 371-380

80. Katusic ZS (2001) Vascular endothelial dysfunction: does tetrahydrobiopterin play a role? Am J Physiol Heart Circ Physiol 281: H981-986.

81. Milstien S, Katusic Z (1999) Oxidation of tetrahydrobiopterin by peroxynitrite: implications for vascular endothelial function. Biochem Biophys Res Commun 263: 681-684.

82. Bauer PM, Fulton D, Boo YC, Sorescu GP, Kemp BE, et al. (2003) Compensatory phosphorylation and protein-protein interactions revealed by loss of function and gain of function mutants of multiple serine phosphorylation sites in endothelial nitric-oxide synthase. J Biol Chem 278: 14841-14849.

83. Dudzinski DM, Michel T (2007) Life history of eNOS: partners and pathways. Cardiovasc Res 75: 247-260

84. Hashiguchi A, Yano S, Morioka M, Hamada J, Kochi M, et al. (2005) Dephosphorylation of eNOS on Thr495 after transient forebrain ischemia in gerbil hippocampus. Brain Res Mol Brain Res 133: 317-319.

85. Chen CA, Druhan LJ, Varadharaj S, Chen YR, Zweier JL (2008) Phosphorylation of endothelial nitric-oxide synthase regulates superoxide generation from the enzyme. J Biol Chem 283: 27038-27047.

86. Park SL, Lee DH, Yoo SE, Jung YS (2010) The effect of $\mathrm{Na}\left({ }^{+}\right) / H\left({ }^{+}\right)$exchanger-1 inhibition by sabiporide on blood-brain barrier dysfunction after ischemia/ hypoxia in vivo and in vitro. Brain Res 1366: 189-196.

87. Brown RC, Davis TP (2005) Hypoxia/aglycemia alters expression of occludin and actin in brain endothelial cells. Biochem Biophys Res Commun 327: 1114 1123.

88. Yun HY, Dawson VL, Dawson TM (1996) Neurobiology of nitric oxide. Crit Rev Neurobiol 10: 291-316.

89. Garthwaite J, Boulton CL (1995) Nitric oxide signaling in the central nervous system. Annu Rev Physiol 57: 683-706.

90. ladecola C, Zhang F, Casey R, Clark HB, Ross ME (1996) Inducible nitric oxide synthase gene expression in vascular cells after transient focal cerebra ischemia. Stroke 27: 1373-1380.

91. Rubanyi GM, Polokoff MA (1994) Endothelins: molecular biology, biochemistry pharmacology, physiology, and pathophysiology. Pharmacol Rev 46: 325-415

92. Ziv I, Fleminger G, Djaldetti R, Achiron A, Melamed E, Sokolovsky M (1992) Increased plasma endothelin-1 in acute ischemic stroke. Stroke 23: 1014-1016.

93. Barone FC, Globus MY, Price WJ, White RF, Storer BL, et al. (1994) Endothelin levels increase in rat focal and global ischemia. J Cereb Blood Flow Metab 14 337-342.

94. Bian LG, Zhang TX, Zhao WG, Shen JK, Yang GY (1994) Increased endothelin-1 in the rabbit model of middle cerebral artery occlusion. Neurosci Lett 174: 47-50.

95. Ehrenreich $H$, Schilling $L$ (1995) New developments in the understanding of cerebral vasoregulation and vasospasm: the endothelin-nitric oxide network. Cleve Clin J Med 62: 105-116.

96. D'Orleans-Juste P, Claing A, Warner TD, Yano M, Telemaque S (1993) Characterization of receptors for endothelins in the perfused arterial and venous mesenteric vasculatures of the rat. $\mathrm{Br} J$ Pharmacol 110: 687-692.

97. Barone FC, Willette RN, Yue TL, Feurestein G (1995) Therapeutic effects of endothelin receptor antagonists in stroke. Neurol Res 17: 259-264. 
Citation: Palomares SM, Cipolla MJ (2011) Vascular Protection Following Cerebral Ischemia and Reperfusion. J Neurol Neurophysiol S1. doi:10.4172/2155-9562.S1-004

98. Dawson DA, Sugano H, McCarron RM, Hallenbeck JM, Spatz M (1999) Endothelin receptor antagonist preserves microvascular perfusion and reduces ischemic brain damage following permanent focal ischemia. Neurochem Res 24: $1499-1505$.

99. Matsuo Y, Mihara S, Ninomiya M, Fujimoto M (2001) Protective effect of endothelin type A receptor antagonist on brain edema and injury after transient middle cerebral artery occlusion in rats. Stroke 32: 2143-2148.

100.Leung JW, Chung SS, Chung SK (2009) Endothelial endothelin-1 overexpression using receptor tyrosine kinase tie-1 promoter leads to more severe vascular permeability and blood brain barrier breakdown after transient middle cerebral artery occlusion. Brain Res 1266: 121-129.

101. Kawai N, McCarron RM, Spatz M (1995) Endothelins stimulate sodium uptake into rat brain capillary endothelial cells through endothelin A-like receptors. Neurosci Lett 190: 85-88.

102. Stanimirovic DB, Bertrand N, McCarron R, Uematsu S, Spatz M (1994) Arachidonic acid release and permeability changes induced by endothelins in human cerebromicrovascular endothelium. Acta Neurochir Suppl (Wien) 60: 71-75.

103. Hossmann KA (2006) Pathophysiology and therapy of experimental stroke. Cell Mol Neurobiol 26: 1057-1083.

104. Liebeskind DS (2003) Collateral circulation. Stroke 34: 2279-2284.

105. Caplan LR, Hennerici M (1998) Impaired clearance of emboli (washout) is an important link between hypoperfusion, embolism, and ischemic stroke. Arch Neurol 55: 1475-1482.

106. Wang CX, Todd KG, Yang Y, Gordon T, Shuaib A (2001) Patency of cerebra microvessels after focal embolic stroke in the rat. J Cereb Blood Flow Metab 21: 413-421.

107. Hoehn-Berlage M, Norris DG, Kohno K, Mies G, Leibfritz D, et al. (1995) Evolution of regional changes in apparent diffusion coefficient during focal ischemia of rat brain: the relationship of quantitative diffusion NMR imaging to reduction in cerebral blood flow and metabolic disturbances. J Cereb Blood Flow Metab 15: 1002-1011.

108. Hossmann KA (1994) Viability thresholds and the penumbra of focal ischemia Ann Neurol 36: 557-565.

109.Symon L, Branston NM, Strong AJ, Hope TD (1977) The concepts of thresholds of ischaemia in relation to brain structure and function. $\mathrm{J}$ Clin Pathol Suppl (R Coll Pathol) 11: 149-154.

110. Hakim AM (1987) The cerebral ischemic penumbra. Can J Neurol Sci 14: $557-$ 559.

111. Moskowitz MA, Lo EH, ladecola C (2010) The science of stroke: mechanisms in search of treatments. Neuron 67: 181-198.

112. Lo EH (2008) A new penumbra: transitioning from injury into repair after stroke. Nat Med 14: 497-500

113. Rennels ML, Nelson E (1975) Capillary innervation in the mammalian central nervous system: an electron microscopic demonstration. Am J Anat 144: 233241.

114. Cohen Z, Bonvento G, Lacombe P, Hamel E (1996) Serotonin in the regulation of brain microcirculation. Prog Neurobiol 50: 335-362.

115. Cipolla MJ, Li R, Vitullo L (2004) Perivascular innervation of penetrating brain parenchymal arterioles. J Cardiovasc Pharmacol 44: 1-8

116. Nishimura N, Schaffer CB, Friedman B, Lyden PD, Kleinfeld D (2007) Penetrating arterioles are a bottleneck in the perfusion of neocortex. Proc Natl Acad Sci U S A 104: 365-370.

117. You J, Johnson TD, Marrelli SP, Bryan RM, Jr. (1999) Functional heterogeneity of endothelial P2 purinoceptors in the cerebrovascular tree of the rat. Am J Physiol 277: H893-900.

118. Shih AY, Friedman B, Drew PJ, Tsai PS, Lyden PD, Kleinfeld D (2009) Active dilation of penetrating arterioles restores red blood cell flux to penumbral neocortex after focal stroke. J Cereb Blood Flow Metab 29: 738-751.
119. Cipolla MJ (2006) Stroke and the Blood-Brain Interface. In: Blood-Brain Barrier Interfaces. R. Dermietzel, D. Spray and M. Nedergaard, Wiley Press, Weinheim.

120. del Zoppo GJ (2006) Stroke and neurovascular protection. N Engl J Med 354 553-555.

121. Wang CX, Shuaib A (2007) Critical role of microvasculature basal lamina in ischemic brain injury. Prog Neurobiol 83: 140-148.

122. del Zoppo GJ (2008) Virchow's triad: the vascular basis of cerebral injury. Rev Neurol Dis 5 Suppl 1: S12-21.

123. Hauck EF, Apostel S, Hoffmann JF, Heimann A, Kempski O (2004) Capillary flow and diameter changes during reperfusion after global cerebral ischemia studied by intravital video microscopy. J Cereb Blood Flow Metab 24: 383-391.

124. Little JR, Kerr FW, Sundt TM, Jr. (1975) Microcirculatory obstruction in foca cerebral ischemia. Relationship to neuronal alterations. Mayo Clin Proc 50 $264-270$

125. del Zoppo GJ, Schmid-Schonbein GW, Mori E, Copeland BR, Chang CM (1991) Polymorphonuclear leukocytes occlude capillaries following middle cerebral artery occlusion and reperfusion in baboons. Stroke 22: 1276-1283.

126. Yemisci M, Gursoy-Ozdemir Y, Vural A, Can A, Topalkara K, et al. (2009) Pericyte contraction induced by oxidative-nitrative stress impairs capillary reflow despite successful opening of an occluded cerebral artery. Nat Med 15: 1031-1037.

127. Hallenbeck JM, Dutka AJ, Tanishima T, Kochanek PM, Kumaroo KK, et al. (1986) Polymorphonuclear leukocyte accumulation in brain regions with low blood flow during the early postischemic period. Stroke 17: 246-253.

128. Liang D, Bhatta S, Gerzanich V, Simard JM (2007) Cytotoxic edema: mechanisms of pathological cell swelling. Neurosurg Focus 22: E2.

129. Simard JM, Chen M, Tarasov KV, Bhatta S, Ivanova S, et al. (2006) Newly expressed SUR1-regulated NC(Ca-ATP) channel mediates cerebral edema after ischemic stroke. Nat Med 12: 433-440.

130. del Zoppo GJ, Mabuchi T (2003) Cerebral microvessel responses to focal ischemia. J Cereb Blood Flow Metab 23: 879-894.

131.Lakhan SE, Kirchgessner A, Hofer M (2009) Inflammatory mechanisms in ischemic stroke: therapeutic approaches. J Transl Med 7: 97.

132. Denes A, Thornton P, Rothwell NJ, Allan SM (2010) Inflammation and brain injury: acute cerebral ischaemia, peripheral and central inflammation. Brain Behav Immun 24: 708-723.

133. Peters K, Unger RE, Brunner J, Kirkpatrick CJ (2003) Molecular basis of endothelial dysfunction in sepsis. Cardiovasc Res 60: 49-57.

134. Ahmad M, Graham SH (2010) Inflammation After Stroke: Mechanisms and Therapeutic Approaches. Transl Stroke Res 1: 74-84.

135. Rosell A, Lo EH (2008) Multiphasic roles for matrix metalloproteinases after stroke. Curr Opin Pharmacol 8: 82-89.

136. Williams LS, Rotich J, Qi R, Fineberg N, Espay A, et al. (2002) Effects of admission hyperglycemia on mortality and costs in acute ischemic stroke. Neurology 59: 67-71.

137. Matz K, Keresztes K, Tatschl C, Nowotny M, Dachenhausenm A, et al. (2006) Disorders of glucose metabolism in acute stroke patients: an underrecognized problem. Diabetes Care 29: 792-797.

138. Kernan WN, Viscoli CM, Inzucchi SE, Brass LM, Bravata DM, et al. (2005) Prevalence of abnormal glucose tolerance following a transient ischemic attack or ischemic stroke. Arch Intern Med 165: 227-233.

139. Gray CS, Scott JF, French JM, Alberti KG, O'Connell JE (2004) Prevalence and prediction of unrecognised diabetes mellitus and impaired glucose tolerance following acute stroke. Age Ageing 33: 71-77.

140.Pulsinelli WA, Waldman S, Rawlinson D, Plum F (1982) Moderate hyperglycemia augments ischemic brain damage: a neuropathologic study in the rat. Neurology 32: 1239-1246. 
Citation: Palomares SM, Cipolla MJ (2011) Vascular Protection Following Cerebral Ischemia and Reperfusion. J Neurol Neurophysiol S1. doi:10.4172/2155-9562.S1-004

141. Capes SE, Hunt D, Malmberg K, Pathak P, Gerstein HC (2001) Stress hyperglycemia and prognosis of stroke in nondiabetic and diabetic patients: a systematic overview. Stroke 32: 2426-2432.

142. Quast MJ, Wei J, Huang NC, Brunder DG, Sell SL, et al. (1997) Perfusion deficit parallels exacerbation of cerebral ischemia/reperfusion injury in hyperglycemic rats. J Cereb Blood Flow Metab 17: 553-559.

143. Bruno A, Liebeskind D, Hao Q, Raychev R (2010) Diabetes Mellitus, Acute Hyperglycemia, and Ischemic Stroke. Curr Treat Options Neurol 12: 492-503.

144. Mandarino LJ, Finlayson J, Hassell JR (1994) High glucose downregulates glucose transport activity in retinal capillary pericytes but not endothelial cells. Invest Ophthalmol Vis Sci 35: 964-972.

145. Martini SR, Kent TA (2007) High glucose downregulates glucose transport activity in retinal capillary pericytes but not endothelial cells. J Cereb Blood Flow Metab 27: 435-451.

146. Brownlee M (2001) Biochemistry and molecular cell biology of diabetic complications. Nature 414: 813-820.

147. Kawai N, Keep RF, Betz AL (1997) Hyperglycemia and the vascular effects of cerebral ischemia. Stroke 28: 149-154.

148. Venables GS, Miller SA, Gibson G, Hardy JA, Strong AJ (1985) The effects of hyperglycaemia on changes during reperfusion following focal cerebral ischaemia in the cat. J Neurol Neurosurg Psychiatry 48: 663-669.

149. Berger L, Hakim AM (1986) The association of hyperglycemia with cerebra edema in stroke. Stroke 17: 865-871.

150. Dietrich WD, Alonso O, Busto R (1993) Moderate hyperglycemia worsens acute blood-brain barrier injury after forebrain ischemia in rats. Stroke 24 : 111-116.

151. Cipolla MJ, Huang Q, Sweet JG (2011) Inhibition of PKC $\beta$ prevents increased blood-brain barrier permeability and edema formation during hyperglycemic stroke. Stroke[article in press]

152. Ennis SR, Keep RF (2007) Effect of sustained-mild and transient-severe hyperglycemia on ischemia-induced blood-brain barrier opening. J Cereb Blood Flow Metab 27: 1573-1582.

153. Kamada H, Yu F, Nito C, Chan PH (2007) Influence of hyperglycemia on oxidative stress and matrix metalloproteinase- 9 activation after focal cerebral ischemia/reperfusion in rats: relation to blood-brain barrier dysfunction. Stroke 38: 1044-1049.

154. Clarke H, Marano CW, Peralta Soler A, Mullin JM (2000) Modification of tight junction function by protein kinase C isoforms. Adv Drug Deliv Rev 41: 283301.

155. Yuan Y, Huang Q, Wu HM (1997) Myosin light chain phosphorylation: modulation of basal and agonist-stimulated venular permeability. Am J Physio 272: $\mathrm{H} 1437-1443$

156. Muir KW, Tyrrell P, Sattar N, Warburton E (2007) Inflammation and ischaemic stroke. Curr Opin Neurol 20: 334-342.

157. Emsley HC, Smith CJ, Tyrrell PJ, Hopkins SJ (2008) Inflammation in acute ischemic stroke and its relevance to stroke critical care. Neurocrit Care 9: 125 138.

158. Banwell V, Sena ES, Macleod MR (2009) Systematic review and stratified meta-analysis of the efficacy of interleukin-1 receptor antagonist in animal models of stroke. J Stroke Cerebrovasc Dis 18: 269-276.

159. Spera PA, Ellison JA, Feuerstein GZ, Barone FC (1998) IL-10 reduces rat brain injury following focal stroke. Neurosci Lett 251: 189-192.

160. Sprague AH, Khalil RA (2009) Inflammatory cytokines in vascular dysfunction and vascular disease. Biochem Pharmacol 78: 539-552.

161. Iversen PO, Nicolaysen A, Kvernebo K, Benestad HB, Nicolaysen G (1999) Human cytokines modulate arterial vascular tone via endothelial receptors. Pflugers Arch 439: 93-100

162. van der Poll T, Lowry SF (1995) Tumor necrosis factor in sepsis: mediator of multiple organ failure or essential part of host defense? Shock 3: 1-12.

163. Vila E, Salaices M (2005) Cytokines and vascular reactivity in resistance arteries. Am J Physiol Heart Circ Physiol 288: H1016-1021.

164. Tureen J (1995) Effect of recombinant human tumor necrosis factor-alpha on cerebral oxygen uptake, cerebrospinal fluid lactate, and cerebral blood flow in the rabbit: role of nitric oxide. J Clin Invest 95: 1086-1091.

165. Hallenbeck JM (2002) The many faces of tumor necrosis factor in stroke. Nat Med 8: 1363-1368.

166. Pretnar-Oblak J, Sabovic M, Pogacnik T, Sebestjen M, Zaletel M (2006) Flow-mediated dilatation and intima-media thickness in patients with lacunar infarctions. Acta Neurol Scand 113: 273-277.

167.Pretnar-Oblak J, Sabovic M, Sebestjen M, Pogacnik T, Zaletel M (2006) Influence of atorvastatin treatment on L-arginine cerebrovascular reactivity and flow-mediated dilatation in patients with lacunar infarctions. Stroke 37 2540-2545.

168. Pretnar-Oblak J, Zaletel M, Zvan B, Sabovic M, Pogacnik T (2006) Cerebrovascular reactivity to L-arginine in patients with lacunar infarctions. Cerebrovasc Dis 21: 180-186.

169. Cipolla MJ, Sweet JG, Gardner-Morse I (2011) Effect of circulating factors on cerebral artery function during hyperglycemic stroke. The FASEB Journal 25 10246 